\title{
Assessment and Code Considerations for the Combined Effect of Seismic Base Isolation and Viscoelastic Dampers
}

\author{
Aykut Erkal, ${ }^{1}$ Semih S. Tezcan, ${ }^{2}$ and Debra F. Laefer ${ }^{3}$ \\ ${ }^{1}$ Department of Architecture and Civil Engineering, University of Bath, Bath BA2 7AY, UK \\ ${ }^{2}$ Civil Engineering Department, Boğaziçi University, Bebek, Istanbul 34342, Turkey \\ ${ }^{3}$ Urban Modelling Group, School of Civil, Structural, and Environmental Engineering, University College Dublin, Dublin 4, Ireland
}

Correspondence should be addressed to Aykut Erkal, ae301@bath.ac.uk

Received 20 June 2011; Accepted 3 August 2011

Academic Editor: D. Huang

Copyright (C) 2011 Aykut Erkal et al. This is an open access article distributed under the Creative Commons Attribution License, which permits unrestricted use, distribution, and reproduction in any medium, provided the original work is properly cited.

\begin{abstract}
To propose an initial formulation for the passive control section of the Turkish Earthquake Code, the impact of base isolation and viscoelastic dampers on a four-storey reinforced concrete $(\mathrm{RC})$ frame building was considered under various one-dimensional quake excitations. Both statically equivalent seismic load methods (comparing Turkish Earthquake code with Uniform Building Code) and linear time history analyses were applied to the RC building based on a portion of the 1999 Kocaeli Earthquake ground motion record (modified to possess predominant spectral periods of $T_{1}=0.13 \mathrm{sec}$ and $T_{2}=1.43 \mathrm{sec}$ representing hard and soft soil conditions, resp.). Effective peak ground acceleration was set to $0.40 \mathrm{~g}$. Time history variations of upper column dis-placements and bending moments were compared, as well as storey drift ratios. Reductions of the fixed-base case column bending moments were obtained of up to $73 \%$ under base isolation, up to $25 \%$ with viscoelastic dampers, and up to $83 \%$ (with a unified response reduction factor) when both devices were both present.
\end{abstract}

\section{Introduction}

How to help buildings absorb seismic energy is a major topic in the structural engineering community. In response to this, a wide variety of novel devices have been developed. In particular, the benefits of seismic isolation resulted in the design and construction of several base-isolated structures $[1,2]$, which as early as the mid-1980s, necessitated new provisions in building codes, only some of which have emerged. For example, despite Turkey's high seismic vulnerability, to date, there are no code provisions with respect to the design of structures with energy dissipation devices. Arguably, this penalizes such projects from a cost perspective. Given that quantification of the effectiveness of isolation devices individually (and more so in combination with each other) has not been fully established, the following study was an attempt to begin to fill this knowledge gap with respect to proposing a formulation to Turkish Earthquake Code (TDY07) [3]. This is done by computationally comparing the seismic response of a fixed-base reinforced concrete frame with base-isolation, viscous dampers, and combined device usage. This comparison was done under earthquake ground motions with different durations of shaking, each with two distinct predominant spectral periods.

\section{Background}

In conventional seismic design, acceptable structural performance is based on its lateral force resisting system being able to absorb and dissipate multiple loading cycles of earthquake energy in a stable manner. In traditional structural design, energy dissipation occurs in specific portions of a structural frame, namely, the plastic hinges, which are often irreparably damaged after such loading [4].

Alternatively, seismic isolation is a passive energy dissipation system that employs base-isolation components at the structure's foundation level [5]. Base isolation is characterized by flexibility and an ability to absorb a major portion of the earthquake energy so that inelastic action does not occur in the structure. By introducing a flexible, lateral plane near the structure's base, the structure's fundamental 


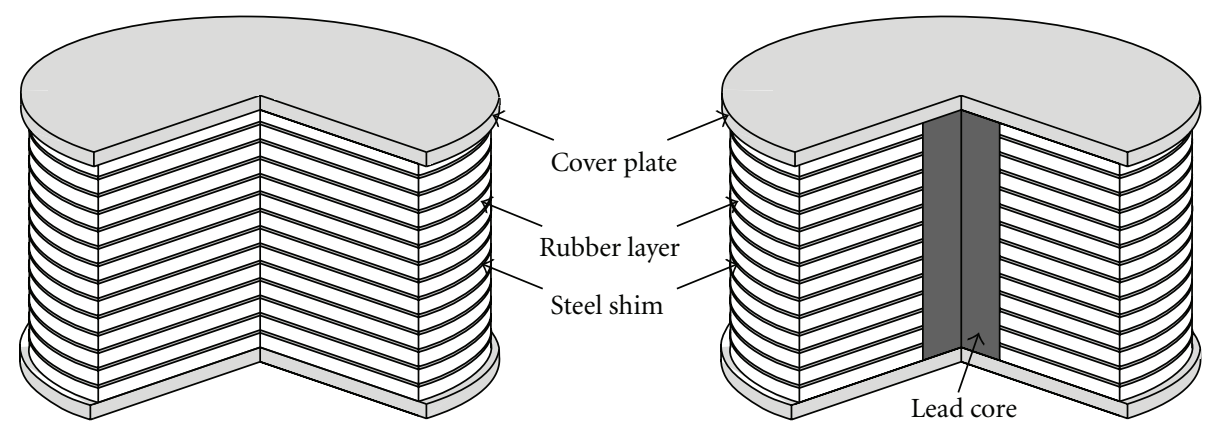

(a) Multilayer elastomeric bearing

(b) Lead-plug bearing

FIGURE 1: Elastomeric bearings.

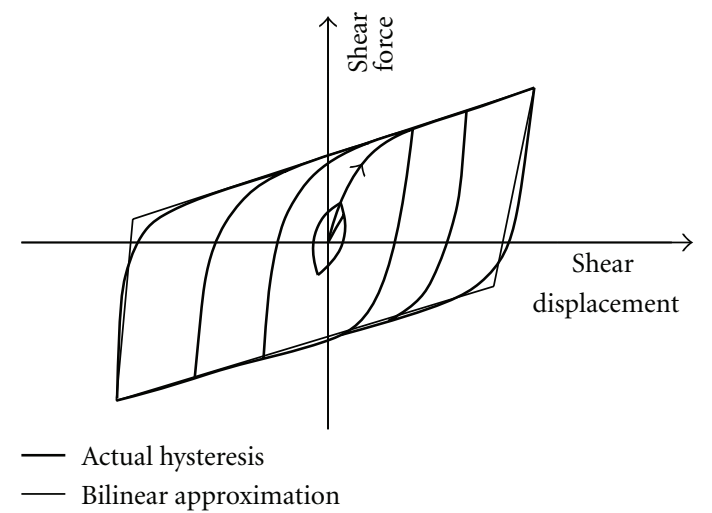

FIGURE 2: Lead-plug bearing hysteresis.

period is significantly lengthened (to two seconds or higher), thereby shifting it away from the destructive frequency range of ground motions, which causes resonance. By using base isolation, fundamental period increases of 1.5-3 times are typical, while damping increases from a few percentages to more than $15 \%$. Additionally, isolator response is assumed to be independent of its deformation history meaning that fully developed isolator flexibility and damping is assumed to act during the entire duration of strong ground shaking [5], thereby enhancing the benefit by providing longer-term protection.

Despite earlier attempts [6-8], seismic isolation became a practical reality, with the development of multilayer elastomeric bearings in the 1980s. These are made with vulcanized bonding of natural rubber or neoprene sheets interleaved with thin reinforcing steel plates called shims (Figure 1(a)). Their development was an extension of usage of elastomeric bearings for bridge and building vibration isolation. Multilayer elastomeric bearings are very stiff and strong in the vertical direction but flexible horizontally, thereby enabling the building to move laterally under strong ground motions.

Within those, one or more lead-plug bearings can be added for further energy absorption. The steel plates within the bearing cause the lead-plug to deform in shear, thereby providing damping (Figure 1(b)) [9, 10], whose behavior can be seen in Figure 2. As an example, Makris and Zhang studied the seismic response of a highway overcrossing located in southern California [11]. The longitudinal forces at the back wall were reduced by one-half when the bridge was isolated with elastomeric bearings at the end abutments.

As an alternative to structural isolation, passive energy control systems can be introduced. These mechanical devices are either installed between the structure's base and the ground, to provide controllable system damping [12], or are incorporated into the frame of the structure to dissipate energy throughout its height [13]. Energy can be dissipated through a wide range of options including yielding of mild steel, sliding friction plates, piston motion, or by a plate within a viscous fluid, orificing of fluid, or by viscoelastic action in polymeric materials $[14,15]$.

Energy dissipation systems are mainly hysteretic or viscoelastic. Hysteretic systems dissipate energy through a mechanism independent of load rate and include metallic dampers utilizing yielding metals as the dissipative mechanism and friction dampers that generate heat through dry sliding friction plates. As the simplest models of hysteretic behavior involve direct relations between force and displacement, they are often called displacement-dependent systems. Another group consists of viscoelastic solid materials, which unlike base isolators can be effective at low displacement levels and operate on the principle of fluid orificing (e.g., viscous fluid dampers) or by deformation of viscoelastic fluids (Figure 3) [16, 17]. Figure 4 shows the force-displacement loops of these devices. In many applications, their behavior is confined to the linear range, which often greatly simplifies the required analysis procedures. Furthermore, since energy dissipation occurs even for infinitesimal deformations, viscoelastic devices have potential application for both wind and seismic protection. More comprehensive evaluations of analysis methods of structures with damping systems can be found elsewhere $[18,19]$.

Guidelines for the implementation of energy dissipation and damping devices in new buildings were first proposed in 1993 by the Structural Engineers Association of Northern California (SEAONC), in the United States (US) [20]. Subsequently, the Federal Emergency Management Agency (FEMA), also in the US, funded the development of guidelines for the seismic rehabilitation of buildings and seismic analysis methods as presented in FEMA-273 and 


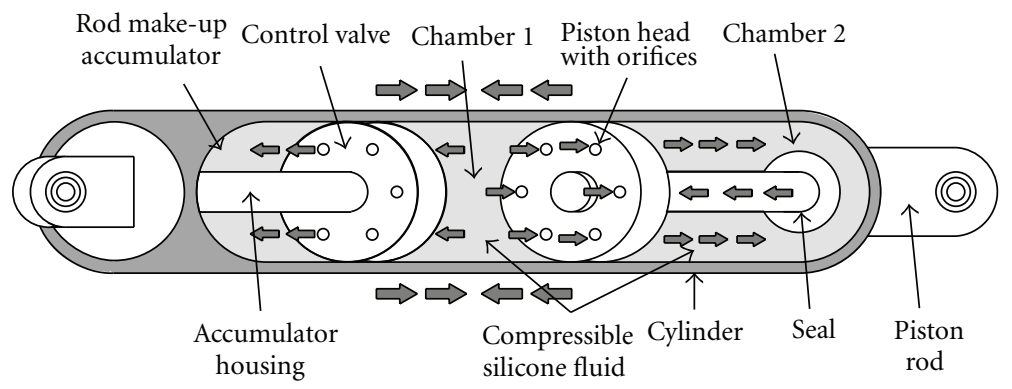

FIGURE 3: Internal mechanism of a viscoelastic fluid damper.

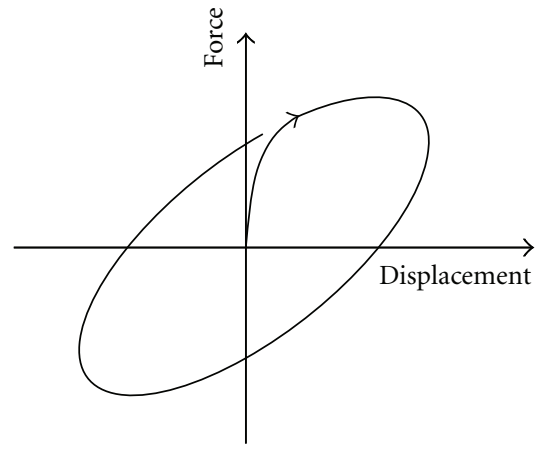

(a) Viscoelastic solid or fluid device

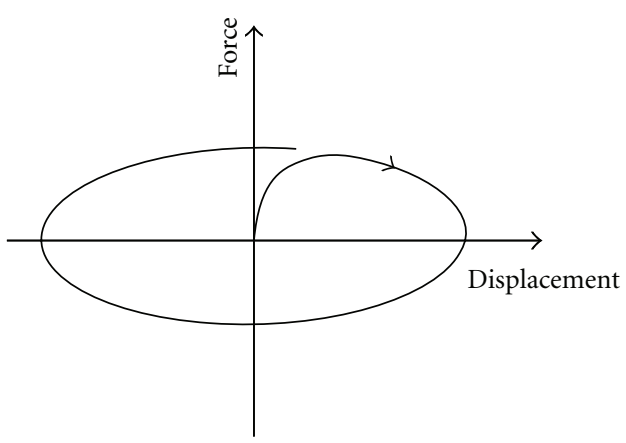

(b) Viscous fluid device

FIGURE 4: Idealized force-displacement loops of viscoelastic energy dissipation devices.

FEMA-274 [21]. In parallel with worldwide proliferation in supplemental energy dissipation devices, a great interest has developed in Turkey to construct buildings with those devices. However, there are no related provisions in the current Turkish Earthquake Code. Therefore, in order to assist in the future modification of the Turkish Earthquake Code, the following study proposes a new formulation to address the individual and combined effects of a selected base isolator (Figure 1(b)) and selected viscoelastic damper (Figure 3) on a representative reinforced-concrete building. Despite the maturity of the technologies, such a study has yet to be published and is, thus, of significance beyond that of local code formulation.

\section{Numerical Simulation of the Effectiveness of Energy Absorbing Devices}

To quantify intervention usefulness, a four-storey, two-bay, reinforced concrete frame building was selected (Figure 5). This is a common building type in Turkey, where buildings are often represented by two-dimensional frames [22, 23]. The model had $3 \mathrm{~m}$ high columns $(0.4 \mathrm{~m} \times 0.7 \mathrm{~m})$ and $5 \mathrm{~m}$ long beams $(0.4 \mathrm{~m} \times 0.5 \mathrm{~m})$. The frame building was $10.7 \mathrm{~m}$ wide and $12 \mathrm{~m}$ high. The concrete's compressive strength was $f_{c}=16.7 \mathrm{MPa}$, and the elasticity modulus of concrete was $E_{c}=30,000 \mathrm{MPa}$, while the steel strength was $f_{s}=191 \mathrm{MPa}$, and the elasticity of steel was $E_{s}=200,000 \mathrm{MPa}$. The total weight of a typical floor was $735.75 \mathrm{kN}$ giving the structure a total weight of $2943 \mathrm{kN}$. A resulting $75 \mathrm{kN} \mathrm{s} / \mathrm{m}$ was assigned as the mass at the top of middle columns at each storey level.

Four scenarios were considered: (i) no intervention, (ii) base isolation, (iii) dampers, and (iv) base isolation with dampers. Firstly, the model was analyzed as a fixedbase case without any passive energy dissipating system. Secondly, isolators were used at the base level of the building. Thirdly, diagonal viscoelastic dampers were installed at each bay of each storey assuming a fixed-base case. Finally, the building was modeled with the base isolation together with viscoelastic dampers installed at each storey. The results were then used to evaluate key assumptions made in building design related to earthquake response.

Given their commercial prominence, lead-plug bearings were selected for building isolation [24]. Because a leadplug bearing's effective stiffness and effective damping both depend on the displacement, the displacement at which a specific damping value occurs can be preselected. In this research, isolators and dampers were modeled by nonlinear link elements, which were used to model local structural nonlinearities in SAP2000 [25]. Additionally, for supplemental damping throughout the height, viscoelastic dampers were chosen because, in many applications, behavior is confined to the linear range to simplify analysis. This approach was also applied in this study.

3.1. Earthquake Loading. Two artificial earthquake records were extracted from the $N$-S component of the ground motion recorded by the Kandilli Observatory Seismograph 


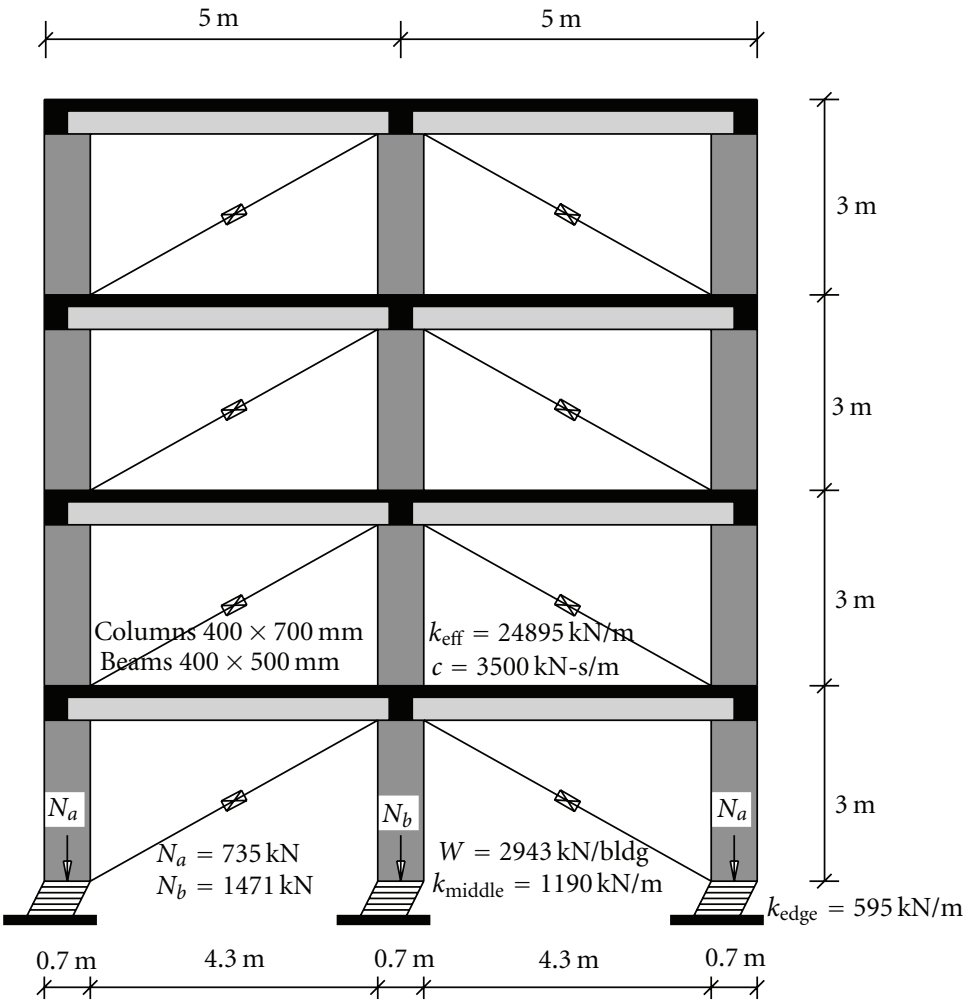

FIgUre 5: Typical frame building.

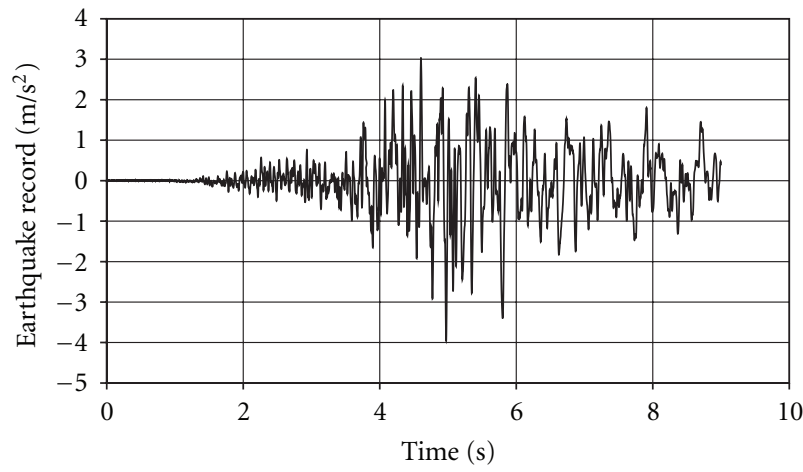

FIgURE 6: Record of earthquake-A.

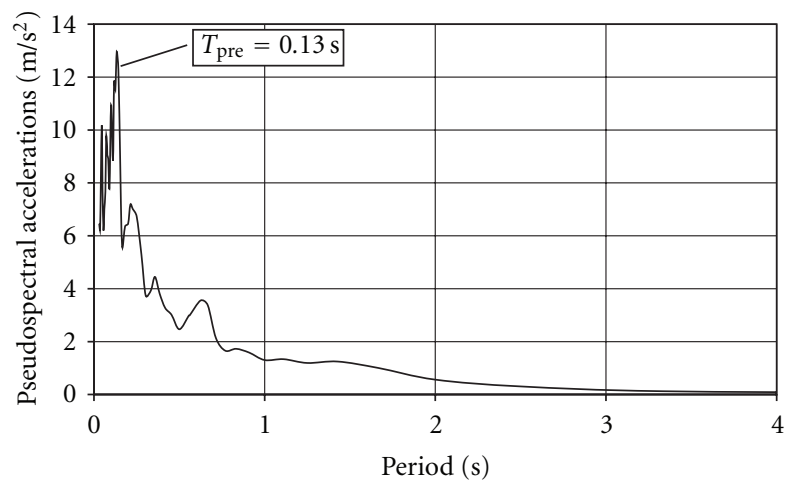

FIGURE 7: Response spectrum of earthquake-A. at the Bursa Tofaş Automobile Factory, during the Kocaeli Earthquake of August 17,1999 [26]. The record included 27,711 data points collected at intervals of $\Delta t=0.005$ seconds over a total duration of $T_{d}=138.55 \mathrm{sec}$. From this, two artificial earthquakes were generated to encompass a range of responses similar to that done by Carneiro et al. [27]. One record was achieved through changing the time interval, $\Delta t$. By shortening or lengthening the time interval, without changing the number of time steps $N$, the predominant period of the soil is either shortened or lengthened, respectively. Similarly, if the maximum acceleration of the earthquake is changed by multiplying all ordinates by a scale factor, the shaking intensity of the earthquake is increased or decreased accordingly. In this way, two characteristic artificial earthquakes, namely, earthquake-A and earthquake-B were produced (Table 1 ). The complete time history record and response spectrum of the earthquake-A is shown in Figures 6 and 7 , respectively.

Artificial earthquakes were used to bracket the building response between soft and stiff soil conditions. In this case, the strong motion portion of the original record was used, which represented approximately 9,000 of the more than 27,700 data points. Thus, $32 \%$ of the data were used to generate artificial earthquakes-A and -B. These had predominant periods of 0.13 seconds and 1.43 seconds, respectively, and both had a maximum acceleration of $3.96 \mathrm{~m} / \mathrm{sec}^{2}$, corresponding to $a_{\max }=0.40 \mathrm{~g}$. The time interval of $\Delta t=0.005$ seconds of the real record was reduced to $\Delta t=0.001$ seconds for earthquake-A and increased 
TABLE 1: Input parameters for earthquake loading.

\begin{tabular}{lccc}
\hline Parameter & Original record & Earthquake-A & Earthquake-B \\
\hline Time step & 0.005 seconds & $0.001 \mathrm{~seconds}$ & $0.01 \mathrm{~seconds}$ \\
Maximum acceleration & $0.1 \mathrm{~g}\left(0.99 \mathrm{~m} / \mathrm{sec}^{2}\right)$ & $0.4 \mathrm{~g}\left(3.96 \mathrm{~m} / \mathrm{sec}^{2}\right)$ & $0.4 \mathrm{~g}\left(3.96 \mathrm{~m} / \mathrm{sec}^{2}\right)$ \\
Predominant period & 0.67 seconds & 0.13 seconds & 1.43 seconds \\
Duration & 138.56 seconds & 9.00 seconds & 90.00 seconds \\
No of data points & 27711 & 9000 & 9000 \\
\hline
\end{tabular}

to $\Delta t=0.01$ seconds for earthquake-B. Decreasing the time step interval $\Delta t$ caused a likewise reduction in the predominant period of the earthquake corresponding to relatively stiff soil conditions. Conversely, the time interval increase generated relatively soft soil conditions.

3.2. Seismic Load Analyses. The structural frames, representing each of the four models described above, were analyzed using the statically equivalent force methods. Because the seismic lateral response procedure for base-isolated structures presented in the International Building Code overestimates the seismic storey force $[28,29]$, comparative analysis was conducted based on the Uniform Building Code (UBC) [30], the Turkish Earthquake Code [3], and a time-history response method, under earthquake- $\mathrm{A}$ and earthquake-B. Based on UBC-97 [30], the distance of the site to the nearest active fault was assumed to be $\Delta \geq 15 \mathrm{~km}$, with an expected magnitude of $\mathrm{M} \geq 7.0$ and slip rate of $\mathrm{SR} \geq$ $5 \mathrm{~mm} /$ year. The site was assumed to be located in Zone 4, the most acute zone in TDY-07; corresponding numerically to the effective horizontal peak bedrock acceleration with $\mathrm{S}_{D}$ soil type (described as a stiff soil profile). Parameters associated with these conditions were used.

What is, thus, proposed is as an addition to Turkish Earthquake Code (TDY-07), which does not currently address base isolation. Specifically, the inclusion of (1) is proposed based on basic vibration mechanics principles with a modifying factor of (2) to address the calculation of displacements for base isolation mechanisms. In this proposed revision of TDY-07, dividing the total base shear for the case $R_{i}=1$ by the lateral stiffness $k_{D}$ given in (1) generates the design level displacement of the base isolators $d_{D}$ of (2). In (1), $k_{D}$ is the minimum base-isolation stiffness that corresponds to the "Design earthquake" response, where

$$
\begin{gathered}
k_{D}=\frac{4 \pi^{2}}{T_{D}^{2}} \frac{W}{g}, \\
d_{D}=\frac{0.063}{B} A_{\circ} g T_{B}^{0.8} T_{D}^{1.2}
\end{gathered}
$$

$W$ is the building's total weight including an appropriate fraction of live load; $g$ is gravity; $B$ is the damping reduction factor; $A_{o}$ is the effective ground acceleration coefficient, which is $A_{o}=0.40$ and $A_{o}=0.30$ for the 1 st and 2nd degree earthquake zones depending on the seismic severity (ground periods greater than $0.40 \mathrm{~g}$ correspond to 1 st degree earthquake zones and those between $0.30 \mathrm{~g}$ and $0.40 \mathrm{~g}$ correspond to $2 \mathrm{nd}$ degree earthquake zones) ( $T_{B}=$ the right-hand side corner period of the spectral curve for the selected soil type and $T_{D}=$ "Design level", target period of the isolated structure). In this example, $T_{B}=0.40$ seconds, corresponding to soil type-Z2 in TDY-07 based on Table 16J of UBC-97 [30] - a well-graded sand or gravel or hard clay; UBC-97 (Section 3.2) [30] was selected over IBC2009 [31], as the later does not explicitly address this issue.

According to UBC-97 [30], however, design level displacements are calculated with

$$
d_{D}=\frac{g C_{V D} T_{D}}{B\left(4 \pi^{2}\right)},
$$

where $C_{V D}$ is the spectral seismic coefficient for baseisolated structural design, and once the diameters and the characteristics of the isolator pads are determined, then the base shear for the design of the isolator devices is calculated according to

$$
V_{D}=\left(\sum k_{D}\right) d_{D}
$$

where $\sum k_{D}$ is the total lateral stiffness of the pads. The implications of such differences are discussed subsequently in this paper.

3.3. Computer Modeling. Lead-plug bearings and viscoelastic dampers were modeled with the "nonlinear properties" (NLPROP) and "nonlinear link elements" (NLLINK) features in SAP2000 [25] - a common modeling approach in this and related programs $[23,32]$. Time history analyses were performed subjecting all four model buildings to two different strong ground motions earthquakes-A and - B, along with a statically equivalent seismic force method.

For the bearings, the generalized restoring force in the isolation bearings is given by

$$
F_{B}=\eta k_{B} d_{u}+(1-\eta) F_{\text {yield }} z+c_{B} \dot{d}_{u},
$$

where $k_{B}$ is the elastic stiffness, $F_{\text {yield }}$ is the yield forces, $\eta$ is the ratio of postyield stiffness to elastic stiffness, $d_{u}$ is the bearing displacement, $z$ is the internal hysteretic variable, and $c_{B}$ is the damping of the bearing [33]. For the bearings in this study, it was assumed that in the region of the design rubber shear strain, the modulus does not change strongly, and thus, the isolators show an approximately linear behavior [27]. Therefore, isolator properties were activated by introducing effective stiffness and effective damping for linear degrees of freedom. The exterior and interior isolators were designed with different stiffnesses $(k)$ as type-a and type-b devices, respectively (Figure 5). The amount of axial 


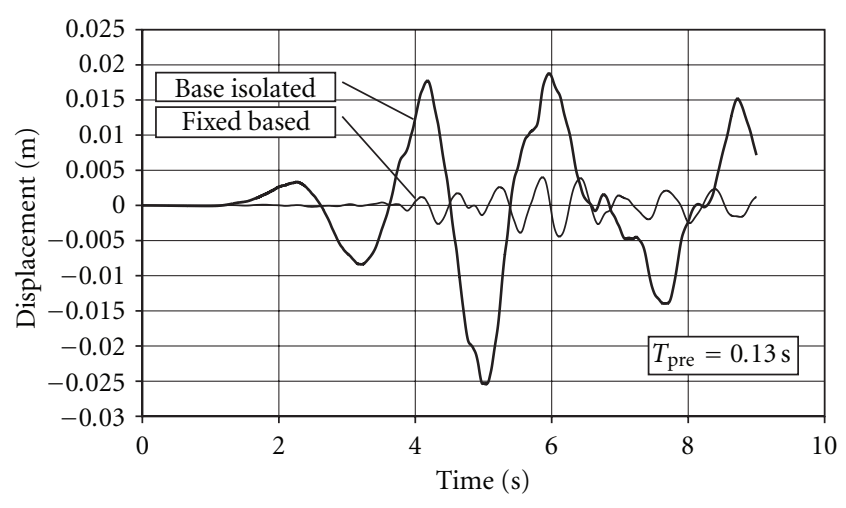

FIgURE 8: Top displacement time histories of the fixed-based and the base-isolated cases.

load, $N_{b}$ in type-b was twice that of type-a, $N_{a}$ (Figure 5). Consequently, the respective lateral stiffnesses were $k_{\text {edge }}=$ $595 \mathrm{kN} / \mathrm{m}$, and $k_{\text {middle }}=1,190 \mathrm{kN} / \mathrm{m}$ and vertical stiffnesses were $k_{\text {edge }}=380,654 \mathrm{kN} / \mathrm{m}$, and $k_{\text {middle }}=639,579 \mathrm{kN} / \mathrm{m}$, with the damping ratio of 0.15 .

Several attempts have been made to model viscous dampers. For example, Makris et al. [34] derived an analytical approximate constitutive relationship for viscoelastic fluid dampers. The force-displacement relationship of the damper was described with the generalized derivative Maxwell model as expressed as (6)

$$
F(t)=\lambda \frac{d^{q} F(t)}{d t^{q}}=C_{0} \frac{d u(t)}{d t},
$$

where $F(t)$ is the force applied at the piston, $\lambda$ relaxation fractional time $C_{0}$ is the zero frequency damping coefficient, $u$ is the piston displacement, and $q$ is the order of derivative. Parameters $\lambda, C_{0}$, and $q$ are determined experimentally [35].

For design purposes in this study, viscoelastic dampers based on the Maxwell model of viscoelasticity were employed. These have either a linear or nonlinear damper in series with a spring. Hence, the nonlinear damper force $F$ is given by

$$
F=k_{\mathrm{eff}} u_{k}=c_{\mathrm{eff}} v^{\exp },
$$

where $k_{\text {eff }}$ and $c_{\text {eff }}$ are the effective values of the stiffness and the coefficient of viscosity, respectively, and they were assumed to be $k_{\text {eff }}=24,895 \mathrm{kN} / \mathrm{m}$ and $c_{\text {eff }}=3,500 \mathrm{kN}$ $\mathrm{sec} / \mathrm{m}$, while $u_{k}$ was the deformation across the spring, and $v$ was the velocity across the damper. The total internal deformation, $d$, of the diagonal link element was the sum of the spring deformation, $u_{k}$, and the damper deformation, $u_{c}$. The damping exponent must be positive and in practicality ranges from 0.2 to 2 . In this study, it was taken as unity, as is commonly done $[23,32]$.

3.4. Effective Critical Damping Ratio. The effective critical damping ratio, $\beta$, supplied by the viscoelastic damping devices was obtained by an analogy to the logarithmic decrement curve for a single-degree-of-freedom (SDOF) system. The displacement versus time curve of an SDOF

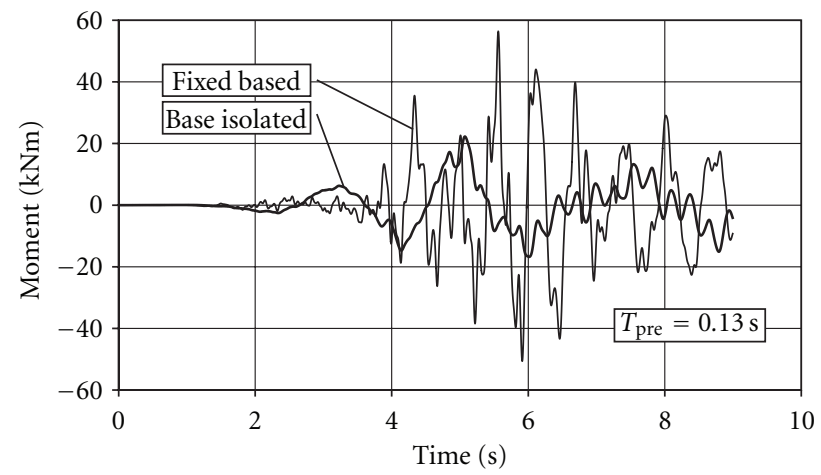

FIGURE 9: Top column upper part bending moment time histories of the fixed-based and the base-isolated cases.

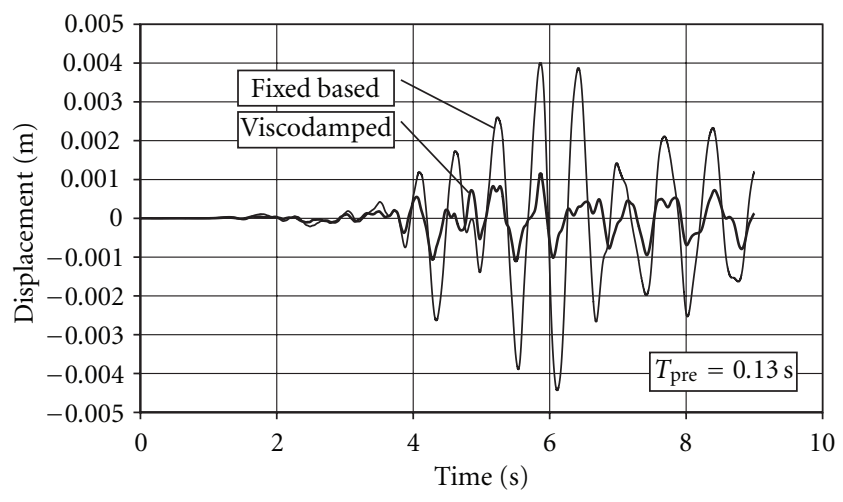

FIgURE 10: Top displacement time histories of the fixed-based and the viscoelastic dampers cases.

system was a decreasing sine curve, from which $\beta$ was calculated by

$$
\operatorname{Ln} \frac{u_{1}}{u_{2}}=\frac{2 \pi \beta}{\sqrt{1-\beta^{2}}},
$$

where $u_{1}=$ the peak displacement at time $t_{1}$, when there was no viscoelastic damper, and $u_{2}=$ the peak displacement, at time $t_{1}$ again, when viscoelastic dampers were installed. Once $u_{1}$ and $u_{2}$ displacements were determined from the models with and without viscoelastic dampers, if $u_{1}$ is taken as the maximum top displacement at time $t$ for the undamped system and $u_{2}$ is the maximum top displacement at the same time $t$, for the damped frame, then the effective damping ratio supplied by the devices becomes $\beta$. The viscoelastic dampers produced an effective damping ratio of $\beta=21.30 \%$ over the entirety of the structure.

3.5. Results. Results are summarized in Table 2 and illustrated in Figures 8-11. The lateral displacements at the top storey were higher for the base isolation and combination cases than those of the fixed-base case due to the low lateral stiffness of the isolators (Figure 8) but much smaller for the intervention case with dampers (Figure 10). However, the bending moments at the upper ends of the columns for all 
TABLE 2: Response of model buildings.

\begin{tabular}{|c|c|c|c|c|c|c|}
\hline \multicolumn{3}{|l|}{ Models } & \multirow{2}{*}{$\begin{array}{c}\begin{array}{c}\text { Fixed } \\
\text { based }\end{array} \\
3.1 \\
\end{array}$} & \multirow{2}{*}{$\begin{array}{c}\begin{array}{c}\text { Base } \\
\text { isolated }\end{array} \\
6.3(25.2)\end{array}$} & \multirow{2}{*}{$\begin{array}{c}\begin{array}{c}\text { Viscoelastic } \\
\text { dampers }\end{array} \\
0.8\end{array}$} & \multirow{2}{*}{$\begin{array}{c}\text { Combination } \\
6.3(25.2)\end{array}$} \\
\hline \multirow{9}{*}{ Forth storey } & \multirow{3}{*}{ Lateral sway $(\mathrm{mm})$} & Eq-A, $T=0.13$ secs & & & & \\
\hline & & $\mathrm{Eq}-\mathrm{B}, T=1.43 \mathrm{secs}$ & 7.3 & $94.6(378.3)$ & 3.1 & $90.4(361.5)$ \\
\hline & & Static equivalent force method & 10.8 & $37.0(147.8)$ & 8.4 & $35.8(143.2)$ \\
\hline & \multirow{3}{*}{ Bending moment $(\mathrm{kNm})$} & Eq-A, $T=0.13$ secs & 43.4 & $5.4(21.7)$ & 7.9 & $2.6(10.5)$ \\
\hline & & Eq-B, $T=1.43$ secs & 81.5 & $65.2(260.6)$ & 24.1 & $36.5(145.9)$ \\
\hline & & Static equivalent force method & 125.7 & $26.0(103.7)$ & 88.7 & $14.8(59.3)$ \\
\hline & \multirow{3}{*}{ Drift ratio $10^{-3}$} & Eq-A, $T=0.13$ secs & 0.17 & $0.025(0.1)$ & 0.04 & $0.015(0.06)$ \\
\hline & & Eq-B, $T=1.43$ secs & 0.47 & $0.40(1.6)$ & 0.17 & $0.24(0.97)$ \\
\hline & & Static equivalent force method & 0.73 & $0.15(0.6)$ & 0.53 & $0.093(0.37)$ \\
\hline \multirow{9}{*}{ Second storey } & \multirow{3}{*}{ Lateral sway (mm) } & Eq-A, $T=0.13$ secs & 1.7 & $6.1(24.5)$ & 0.5 & $6.2(24.7)$ \\
\hline & & Eq-B, $T=1.43$ secs & 3.8 & $91.6(366.2)$ & 1.8 & $88.6(354.5)$ \\
\hline & & Static equivalent force method & 5.5 & $35.8(143.0)$ & 4.5 & $35.1(140.3)$ \\
\hline & \multirow{3}{*}{ Bending moment $(\mathrm{kNm})$} & Eq-A, $T=0.13$ secs & 53.2 & $8.4(33.5)$ & 13.8 & $5.4(21.7)$ \\
\hline & & $\mathrm{Eq}-\mathrm{B}, T=1.43 \mathrm{secs}$ & 111.7 & $121.3(485.1)$ & 52.7 & $77.1(308.3)$ \\
\hline & & Static equivalent force method & 159.3 & $48.1(192.3)$ & 129 & $31.0(123.9)$ \\
\hline & \multirow{3}{*}{ Drift ratio $10^{-3}$} & Eq-A, $T=0.13$ secs & 0.35 & $0.05(0.2)$ & 0.09 & $0.035(0.14)$ \\
\hline & & Eq-B, $T=1.43$ secs & 0.8 & $0.75(3.0)$ & 0.37 & $0.52(2.06)$ \\
\hline & & Static equivalent force method & 1.2 & $0.325(1.3)$ & 0.9 & $0.2(0.83)$ \\
\hline \multirow{5}{*}{ Structural fram } & \multirow{3}{*}{ Base shear $(\mathrm{kN})$} & Eq-A, $T=0.13$ secs & 117.6 & $13.7(54.6)$ & 42.9 & $9.6(38.2)$ \\
\hline & & Eq-B, $T=1.43$ secs & 211.7 & $284.0(1135.8)$ & 131.8 & $188.2(752.8)$ \\
\hline & & Static equivalent force method & 275.2 & $77.5(310.0)$ & 320.8 & $77.5(310.0)$ \\
\hline & Reduction factor $(R)$ & & 8 & $8(2)$ & 8 & $8(2)$ \\
\hline & Period of the building $(T)$ (secs) & & 0.575 & 2.479 & 0.475 & 2.452 \\
\hline
\end{tabular}

Note: time history analyses results were obtained as average of 5 peaks.

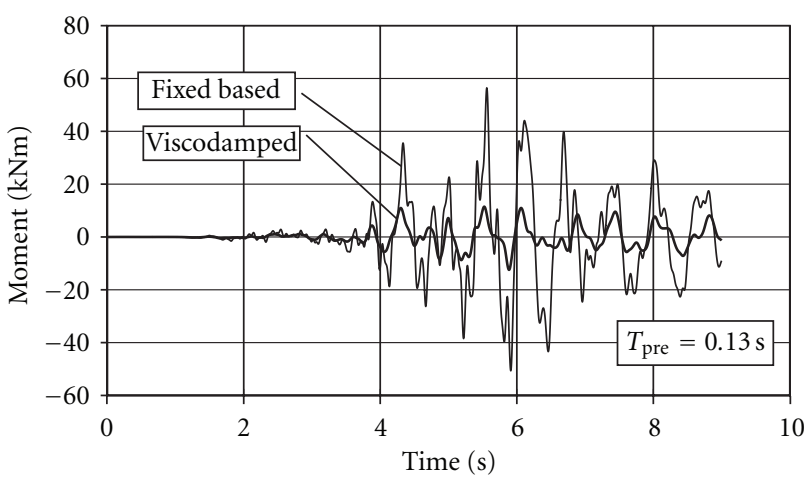

FIGURE 11: Top column upper part bending moment time histories of the fixed-based and the viscoelastic dampers cases.

intervention cases were smaller than those of the fixed-base case (Figures 9 and 11).

When lead-plug bearings were used, the building's fundamental period increased from $T=0.575$ seconds to $T=2.479$ seconds, thereby significantly reducing response. For instance, under statically equivalent loads, the relative storey drift ratio at the 2 nd storey dropped from 1.2 per mil to 0.325 per mil (Figure 12), and the bending moment, $M$, at the exterior column at that level reduced from $159.3 \mathrm{kNm}$ to $48 \mathrm{kNm}$, when a unified response reduction factor of 8 was considered for both cases. The response reduction factor represents a ratio of the maximum seismic force on a structure during a specified ground motion (if it were to remain elastic) to the designed seismic force. Code of practice assumes that some ductile deformation occurs, and this is reflected through the incorporation of the response reduction factor " $R$ " [36].

In the time history analysis, the top storey displacements for the fixed-base case increased approximately 525\%, when the building was base isolated (Figure 8), which is allowable as the intent of the code is to control damage by permitting large displacements and elastic response with low floor accelerations for large earthquake input. Additionally, the upper part of the top columns' bending moments decreased approximately $64 \%$, when only the base isolation was applied (Figure 9). According to the UBC-97 [30], the factor $R$ should be 2 in the base-isolated case and 8 in the fixed-base case. The rationale for this, as will be seen below, is perhaps not fully considered.

When only viscoelastic dampers were used, the building's fundamental period decreased from $T=0.575$ seconds to $T=0.475$ seconds, and the response reduced proportionately. For example, under statically equivalent loads, the relative storey drift ratio at the 2 nd storey dropped from 1.2 per mil to 0.9 per mil (Figure 12), and the bending 


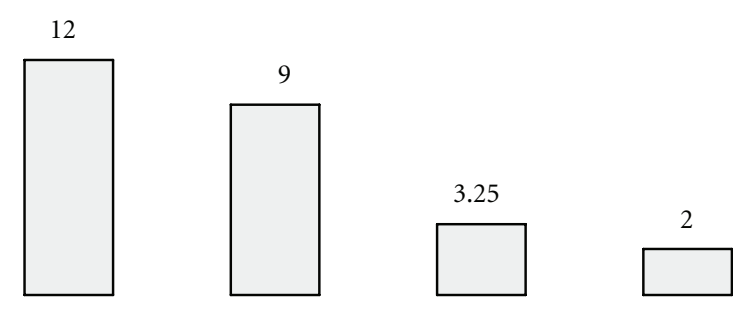

(a) Second story drift ratios (per ten thousand)

159

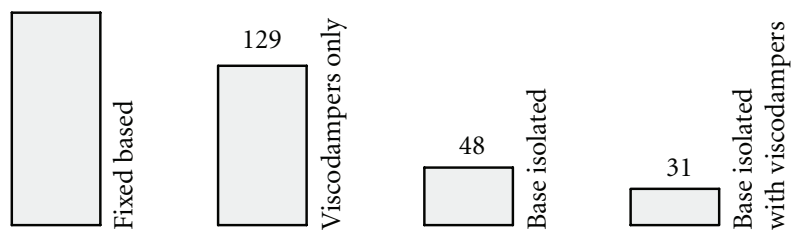

All response values are for a unified reduction factor $(R=8)$

(b) Column bending moments $(\mathrm{kN} / \mathrm{m})$

Figure 12: Relative storey drift ratios and column bending moments at second storey.

moment, $M$, at the exterior column at that level reduced from $159.3 \mathrm{kNm}$ to $129 \mathrm{kNm}$, when a unified response reduction factor of 8 was considered for both cases. Additionally, in the time history analyses, when only viscoelastic dampers were used, the response decreased to $73 \%$ in the top storey displacements of the fixed-base case and to $83 \%$ in the top columns' upper part moment values $(R=8)$.

When both techniques were applied, even better results were obtained; the building's fundamental period increased from $T=0.575$ seconds to $T=2.452$ seconds. The 2 nd storey drift ratio dropped from 1.2 per mil to 0.2 per mil, and the equivalent exterior column bending moment decreased from $159 \mathrm{kNm}$ to $31 \mathrm{kNm}$, when a unified response reduction factor of 8 was considered for both cases (Figure 12). In time history analyses, when viscoelastic dampers were used with base isolation, the top storey displacements for fixedbase case increased approximately $525 \%$, while their bending moments decreased approximately $76 \%$.

Soil type also strongly impacts the results. When the base isolation was used for a building on relatively strong ground, and the predominant spectral period of the input ground motion was in the short period region $(T<\sim$ $0.3-0.5$ seconds), then the impact of base-isolation was most pronounced. The short period region is also called an acceleration sensitive region of the spectrum, because structural response is related most directly to ground acceleration. That spectral region depends on the time variation of ground motion [37]. The effectiveness decreased considerably as the soil softened-in the case of earthquakeB $(T=1.43$ seconds $)$. For example, when the time history analyses were conducted, the base shear for the base-isolated building for the earthquake- $A$ was $54.6 \mathrm{kN}$ but $1,135.8 \mathrm{kN}$ for earthquake-B.

Importantly, the proposed modifications for Code TDY07 in (1) and (2) gave reasonable results. The calculated design level displacement of the isolators was 0.239 , which was $11 \%$ smaller than the $0.270 \mathrm{~m}$ generated using the UBC97 relationships [30]. Similarly, the base shear was $372 \mathrm{kN}$ in TDY-07, also $11 \%$ smaller than the base shear of $418 \mathrm{kN}$ when the UBC-97 [30] was applied. The difference emanates from the small difference in definition of the shear force. In TDY-07 shear force is defined as in (9), while in the UBC (10) is used for a long period $(T>\sim 0.30-0.90 \mathrm{sec})$ [30]; where $C_{V}$ is the seismic coefficient for conventional structures (the same as $C_{V D}$ for base-isolated structures), $I$ is the importance factor, and $T$ is the fundamental period of the structure. The slightly different coefficients in the design response spectrums of the two codes cause mildly divergent results. Additionally, while there are five seismic zones and soil profile categories in UBC-97 [30], only four are available in TDY-07. Despite the differences, the ultimate results can be considered consistent having generated a value being within $11 \%$ of each other

$$
\begin{gathered}
V_{\mathrm{TDY}}=A_{0} \frac{2.5\left(T_{B} / T\right)^{0.8} I}{R} W, \\
V_{\mathrm{UBC}}=\frac{C_{V} I}{R T} W .
\end{gathered}
$$

Additionally, the large lateral displacements imposed by the UBC-97 [30] requirements make designing and implementing seismic isolation rather costly. In fact, assuming a structural reduction factor of $R=2$ in the design of base-isolated structures is overly conservative compared to the conventional fixed base structures, where $R=8$. Whether this additional safety factor is fully needed should be considered further.

\section{Discussion}

In time history analyses, base isolation drastically reduced the time history values of the fixed-base case in column bending moments (up to 64\%), while the displacements increased (up to 525\%) (Figures 8 and 9). This closely matched the $68 \%$ reduction reported by De la Llera et al. (2004) in their investigation of the base isolation of a 6-storey high hospital of the Universidad Catolica in Santiago, Chile where maximum roof acceleration response reduced from $2.10 \mathrm{~g}$ to about $0.67 \mathrm{~g}$ for the fixed-base case versus the isolated one considering a linear response of the superstructure [24]. More dramatic results were reported by Matsagar and Jangid [33] in their investigation of the seismic response of a 5-storey building base-isolated with lead-plug bearings, where reductions up to $84 \%$ were reported under the Loma Prieta, 1989 earthquake. This was due to the fact that $T$ increased from $0.5 \mathrm{sec}$ to $2.5 \mathrm{secs}$, which completely removed the structure from damaging fundamental periods of the applied ground motion of 0.36 secs, 0.52 secs, and 0.64 secs [33].

In the research presented herein, viscoelastic dampers decreased column bending moments up to about $83 \%$ and storey displacements up to about $73 \%$, with a damping ratio of $21.30 \%$ compared to the fixed-base case (Figures 10 and 11). This was significantly more than the approximately 
$50 \%$ in storey displacements reported by Sadek et. al. [38] for the peak response of a three-storey building with and without supplemental dampers at every storey, because that building was analyzed with a wider range of fundamental periods $(0.20,0.75$, and 2.00 secs $)$ [38] Lin et al.'s numerical study of a pair of five-storey, torsionally coupled buildings subjected to five earthquake records from different incident angles also showed less improvement [39]. The time history displacement responses of the top floor were reduced only up to $40 \%$ [39], which closely compared to the $43 \%$ response reduction reported $\mathrm{Wu}$ and Chen on a six-storey shear building with multiple tuned mass dampers [40]. The smaller response reduction for these studies $[39,40]$ derives from the damper type (i.e., tuned mass dampers) versus other studies reporting the impact of viscoelastic dampers.

In the research presented herein, when base isolation was installed in combination with viscoelastic dampers, the building behaved almost as a rigid body. Under statically equivalent loads, while the storey displacements remained almost the same as those of the base-isolated building, column bending moments and second storey drift ratios decreased $80 \%$ and almost $83 \%$, respectively (Figure 12). In these comparisons, a unified response reduction factor of 8 was considered for both fixed and isolated bases combined with viscoelastic dampers. Providakis [32] showed superstructure drift reductions in a six-storey RC building with the supplemental viscous damping under near fault excitations as well. Providakis reported an additional 20$37 \%$ superstructure drift reductions, when the isolated building was supplied with viscous damping [32]. Since, viscoelastic dampers work at low displacements, they work very well with base-isolated structures since base isolation helps reduce displacements. In summary, the work presented herein aligns well with other work published to date.

Comparability of the calculated design level displacements based on UBC97 and TDY-07 with proposed equation also proves the validity of the approach. Basically, dividing the total base shear equation provided in the code by the lateral stiffness (based on basic vibration mechanics principles) renders the calculation of design level displacements for base isolation mechanisms with applicable results. The inclusion of the equation in TDY-07 is considered a useful initiative for the design strategies in Turkey, since current TDY-07 does not currently address base isolation.

\section{Conclusions}

For the future incorporation of design specifications of structures with energy dissipation devices into the Turkish Earthquake Code [3], a typical four-storey reinforced concrete frame building was analyzed under various onedimensional earthquake excitations, quantifying the beneficial effects of passive energy dissipation systems for structural control during seismic events. Viscoelastic dampers and base isolation were introduced individually and jointly and compared to a frame without any intervention. The Uniform Building Code [30] was taken as a basis for all design calculations, and a series of formulations were proposed to supplement TDY-07. The resulting proposed relationships for TDY-07 generated slightly smaller results than the UBC97 [30] and were, thus, found to be of acceptable reliability for further consideration for code inclusion.

A two-bay, four-storey model frame was numerically modeled in SAP2000, bringing more in depth insight into the merits of jointly using viscoelastic dampers and lead-plug bearings as a base-isolation system for aseismic intervention as well. In terms of the building response to the proposed interventions, compared to fixed-base case, displacements and column bending moments were reduced up to $73 \%$ when the structure was base isolated and $25 \%$ when viscoelastic dampers were used by themselves. When the base isolated building was supplied with viscoelastic dampers, the overall reduction was $83 \%$ (with a unified response reduction factor of 8). Since the base isolation decreased the relative storey drift ratios considerably and the viscoelastic dampers were activated at low displacements, viscoelastic dampers worked well in concurrence with the base-isolation. The system was most effective when a base isolated building rested on relatively strong ground.

\section{References}

[1] A. S. Mokha, N. Amin, M. C. Constantinou, and V. Zayas, "Seismic isolation retrofit of large historic building," Journal of Structural Engineering, vol. 122, no. 3, pp. 298-308, 1996.

[2] N. Youssef, "Viscous dampers at multiple levels for the historic preservation of Los Angeles City Hall," Structural Design of Tall Buildings, vol. 10, no. 5, pp. 339-350, 2001.

[3] Turkish Earthquake Code TDY-07, "Specification for buildings to be built in seismic zones," Tech. Rep., Ministry of Public Works and Settlement Government of Republic of Turkey, 2007.

[4] S. R. Tzan and C. P. Pantelides, "Active structures considering energy dissipation through damping and plastic yielding," Computers and Structures, vol. 66, no. 4, pp. 411-433, 1998.

[5] J. P. Stewart, J. P. Conte, and I. D. Aiken, "Observed behavior of seismically isolated buildings," Journal of Structural Engineering, vol. 125, no. 9, pp. 955-964, 1999.

[6] F. Naeim and J. M. Kelly, Design of Seismic Isolated Structures, John Wiley \& Sons, New York, NY, USA, 1st edition, 1999.

[7] S. S. Tezcan, "The use of isolation techniques in design," in Proceedings of the State-of-the-Art in Earthquake Engineering Conference, pp. 1-24, Cambridge University, London, UK, January 1982.

[8] S. S. Tezcan and A. Çivi, "Vibration isolators as a tool to prevent earthquake damage," in Proceedings of the 6th International Conference on Structural Mechanics in Reactor Technology, (6 SMIRT), pp. 1-13, Paris, France, August 1981.

[9] V. A. Matsagar and R. S. Jangid, "Seismic response of baseisolated structures during impact with adjacent structures," Engineering Structures, vol. 25, no. 10, pp. 1311-1323, 2003.

[10] B. Yoo and Y. H. Kim, "Study on effects of damping in laminated rubber bearings on seismic responses for a 1/8 scale isolated test structure," Earthquake Engineering and Structural Dynamics, vol. 31, no. 10, pp. 1777-1792, 2002.

[11] N. Makris and J. Zhang, "Seismic response analysis of a highway overcrossing equipped with elastomeric bearings and fluid dampers," Journal of Structural Engineering, vol. 130, no. 6, pp. 830-845, 2004.

[12] H. Yoshioka, J. C. Ramallo, and B. F. Spencer, "'Smart' base isolation strategies employing magnetorheological dampers," 
Journal of Engineering Mechanics, vol. 128, no. 5, pp. 540-551, 2002.

[13] O. M. Ramirez, M. C. Constantinou, A. S. Whittaker, C. A. Kircher, M. W. Johnson, and C. Z. Chrysostomou, "Validation of the 2000 NEHRP provisions' equivalent lateral force and modal analysis procedures for buildings with damping systems," Earthquake Spectra, vol. 19, no. 4, pp. 981-999, 2003.

[14] G. F. Dargush and R. S. Sant, "Evolutionary aseismic design and retrofit of structures with passive energy dissipation," Earthquake Engineering and Structural Dynamics, vol. 34, no. 13, pp. 1601-1626, 2005.

[15] M. D. Symans, F. A. Charney, A. S. Whittaker et al., "Energy dissipation systems for seismic applications: current practice and recent developments," Journal of Structural Engineering, vol. 134, no. 1, pp. 3-21, 2008.

[16] C. Y. Hou, "Fluid dynamics and behavior of nonlinear viscous fluid dampers," Journal of Structural Engineering, vol. 134, no. 1, pp. 56-63, 2008.

[17] M. C. Constantinou and M. D. Symans, "Experimental study of seismic response of buildings with supplemental fluid dampers," The Structural Design of Tall Buildings, vol. 2, no. 2, pp. 93-132, 1993.

[18] O. M. Ramirez, M. C. Constantinou, J. D. Gomez, A. S. Whittaker, and C. Z. Chrysostomou, "Evaluation of simplified methods of analysis of yielding structures with damping systems," Earthquake Spectra, vol. 18, no. 3, pp. 501-530, 2002.

[19] H. B. Yun, F. Tasbighoo, S. F. Masri et al., "Comparison of modeling approaches for full-scale nonlinear viscous dampers," Journal of Vibration and Control, vol. 14, no. 1-2, pp. 51-76, 2008.

[20] A. S. Whittaker, I. D. Aiken, D. Bergman et al., "Code requirements for the design and implementation of passive energy dissipation systems," in Proceedings of the Seminar on Seismic Isolation, Passive Energy Dissipation and Active Control, vol. 2 of Report Notes on Applied Technology Council, no. 17-1, pp. 497-508, San Francisco, Calif, USA, 1993.

[21] NEHRP Guidelines for the Seismic Rehabilitation of Buildings and NEHRP Com-mentary on the Guidelines for the Seismic Rehabilitation of Buildings, Part 1- Provisions, Part 2-Commentary, Reports Notes FEMA-273 and FEMA-274, Federal Emergency Management Agency, Applied Technology Council, Washington, DC, USA, 1997.

[22] V. K. Agarwal, J. M. Niedzwecki, and J. W. van de Lindt, "Earthquake induced pounding in friction varying base isolated buildings," Engineering Structures, vol. 29, no. 11, pp. 2825-2832, 2007.

[23] S. S. Tezcan and O. Uluca, "Reduction of earthquake response of plane frame buildings by viscoelastic dampers," Engineering Structures, vol. 25, no. 14, pp. 1755-1761, 2003.

[24] J. C. De la Llera, C. Lüders, P. Leigh, and H. Sady, "Analysis, testing, and implementation of seismic isolation of buildings in Chile," Earthquake Engineering and Structural Dynamics, vol. 33, no. 5, pp. 543-574, 2004.

[25] SAP2000 Version 10, Integrated Finite Element Analysis and Design of Structures, Computers and Structures, Berkeley, Calif, USA, 1995.

[26] M. B. Demircioglu and K. Şeşetyan, Earthquake Special, Kandilli Observatory and Earthquake Engineering Research Institute, Boğaziçi University, Bebek, Istanbul, Turkey, 2000, http://www.koeri.boun.edu.tr//depremmuh/default.htm.

[27] J. O. Carneiro, F. J. Q. De Melo, S. Jalali, and P. P. Camanho, "Analytical dynamic analysis of earthquake baseisolation structures using time history modal superposition,"
Proceedings of the Institution of Mechanical Engineers, Part K, vol. 218, no. 1, pp. 39-49, 2004.

[28] F. Khoshnoudian and B. Mehrparvar, "Evaluation of IBC equivalent static procedure for base shear distribution of seismic isolated structures," Journal of Earthquake Engineering, vol. 12, no. 5, pp. 681-703, 2008.

[29] F. Khoshnoudian and S. Esrafili, "A new lateral force distribution formula for base-isolated structures," Proceedings of the Institution of Civil Engineers, vol. 161, no. 5, pp. 277-297, 2008.

[30] "Uniform Building Code UBC-97," in Proceedings of the International Conference of Building Officials, Whittier, Calif, USA, 1997.

[31] IBC 2009, International Building Code, International Code Council, Country Club Hills, Ill, USA, 2009.

[32] C. P. Providakis, "Effect of LRB isolators and supplemental viscous dampers on seismic isolated buildings under nearfault excitations," Engineering Structures, vol. 30, no. 5, pp. 1187-1198, 2008.

[33] V. A. Matsagar and R. S. Jangid, "Seismic response of baseisolated structures during impact with adjacent structures," Engineering Structures, vol. 25, no. 10, pp. 1311-1323, 2003.

[34] N. Makris, M. C. Constantinou, and G. F. Dargush, "Analytical model of viscoelastic fluid dampers," Journal of Structural Engineering, vol. 119, no. 11, pp. 3310-3325, 1993.

[35] N. Makris and H. S. Deoskar, "Prediction of observed response of base-isolated structure," Journal of Structural Engineering, vol. 122, no. 5, pp. 485-492, 1996.

[36] D. Cardone, M. Dolce, and M. Rivelli, "Evaluation of reduction factors for high-damping design response spectra," Bulletin of Earthquake Engineering, vol. 7, no. 1, pp. 273-291, 2009.

[37] A. K. Chopra, Earthquake Dynamics of Structures: A Primer, Earthquake Engineering Research Institute, Oakland, Calif, USA, 2nd edition, 2005.

[38] F. Sadek, B. Mohraz, and M. A. Riley, "Linear procedures for structures with velocity-dependent dampers," Journal of Structural Engineering, vol. 126, no. 8, pp. 887-895, 2000.

[39] C. C. Lin, J. M. Ueng, and T. C. Huang, "Seismic response reduction of irregular buildings using passive tuned mass dampers," Engineering Structures, vol. 22, no. 5, pp. 513-524, 2000.

[40] J. Wu and G. Chen, "Optimization of multiple tuned mass dampers for seismic response reduction," in Proceedings of the 2000 American Control Conference, pp. 519-523, June 2000. 

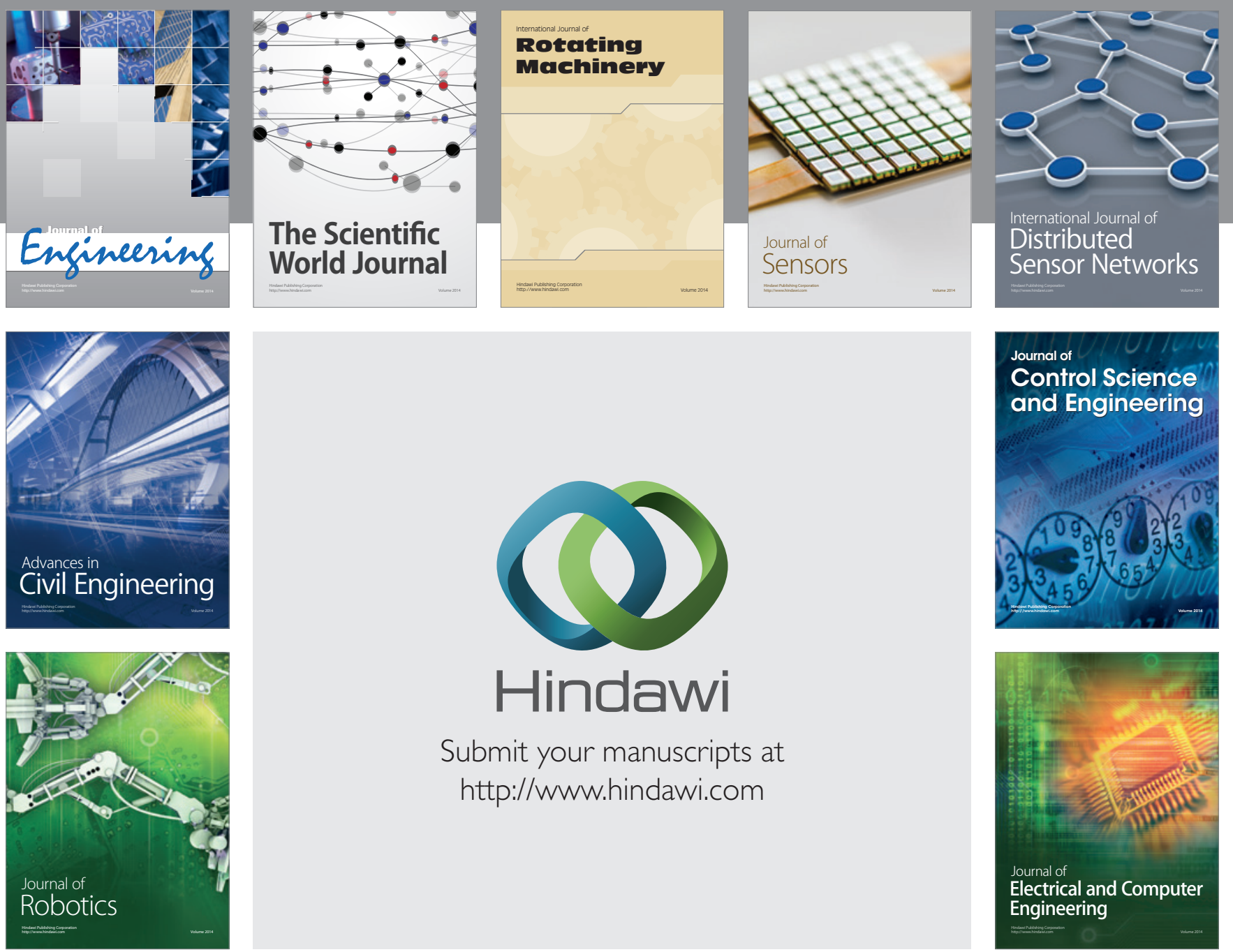

Submit your manuscripts at

http://www.hindawi.com
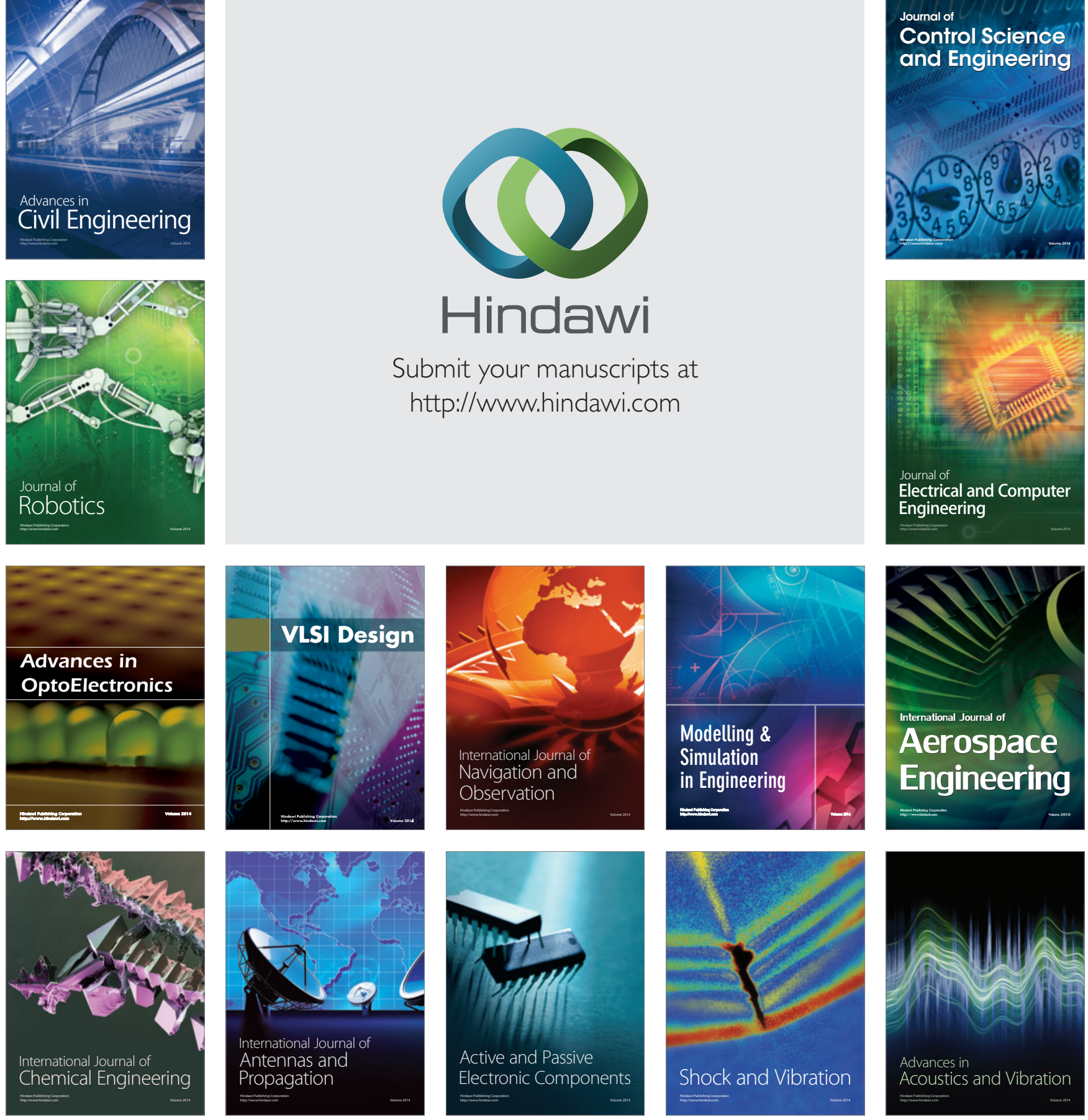